\title{
ENTREVISTA COM TATIANA SALEM LEVY
}

Shirley de Souza Gomes Carreira

Paulo César Silva de Oliveira

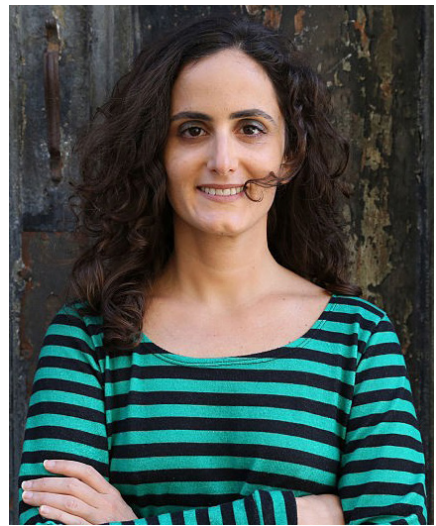

Tatiana Salem Levy é romancista, contista, tradutora, ensaísta e autora de histórias infantis. Seu primeiro livro foi o ensaio $A$ experiência do fora: Blanchot, Foucault e Deleuze, publicado em 2003. Despontou no cenário literário brasileiro com o romance $A$ chave de casa resultante de sua pesquisa de doutorado - que venceu o Prêmio São Paulo de Literatura em 2018. Seu segundo romance, Dois Rios, inspirado em viagens para Córsega e Dois Rios, foi publicado em 2011. Nesse mesmo ano, a autora integrou o volume da revista britânica Granta, dedicado aos 20 melhores jovens escritores brasileiros. Publicou ainda os romances Paraíso (2014) e Vista chinesa (2021). Atualmente, é colunista no jornal Valor Econômico 
e pesquisadora no Instituto de Filosofia da Universidade Nova de Lisboa.

P.: Você estreou em 2007 com A chave de casa, um romance que foi o resultado da sua pesquisa de doutorado, portanto, gestado entre a teoria e a ficção. De que modo a sua formação contribuiu para a escritora que você é hoje?

R.: A minha formação é inseparável de quem sou. Escolhi estudar Letras porque eu amava literatura, porque eu amava ler e sabia que queria escrever. Alguns professores da escola me elogiavam por eu bancar a minha escolha - porque eu tinha nota para entrar em qualquer curso e escolhia um dos mais fáceis de entrar. Só muito mais tarde entendi que nem todo mundo escolhe aquilo de que mais gosta, e isso vale para tudo.

Isso para dizer que ler, estudar literatura, estudar a língua portuguesa, pensar teoria literária, escrever, tudo isso para mim faz parte de um mesmo processo. É verdade que esse processo ganha facetas diversas, ou seja, eu me sinto uma pessoa quando estou escrevendo um texto acadêmico, e outra pessoa quando estou escrevendo um romance.

A decisão de apresentar um romance como tese foi uma tentativa de fazer dialogarem essas linguagens, pois não 
há romance que não se pense a si mesmo. Aos poucos, a universidade tem se aberto cada vez mais para isso. O ensaio tem se mostrado uma interseção interessante, um caminho possível para uma escrita menos dura, mais flexível. Mas também acho que a experiência deve continuar se alargando, pois o pensamento é móvel, e a universidade pode e deve acolher essa mobilidade, pensar nos mais variados formatos.

Enfim, voltando à pergunta, pois já estou fugindo dela: a minha formação me tornou uma leitora melhor, mais crítica e mais aberta (o que, ao meu ver, não é contraditório, muito pelo contrário) e, assim, uma escritora atenta à estrutura e à forma do dizer.

P.: Em A chave de casa, por ser um romance autoficcional, a herança e o sentido de pertencimento são objetivamente abordados. Quanto desse legado transgeracional está presente - se é que está - em seus outros livros?

R.: Cada escritor tem suas obsessões. Essa é uma das minhas, talvez a principal mesmo. Então eu diria que reaparece em todos os meus livros. Em Dois Rios, de forma menos evidente, menos forte, mas está. Os protagonistas, Antonio e Joana, precisam voltar ao passado, compreender 
o que não foi dito nele, para poderem seguir adiante. Em Paraíso, a herança familiar é o centro mesmo do romance: Ana recebe da família uma maldição do século XIX, que passa de geração em geração, até chegar a ela. Só contando a história da escrava que lançou a maldição, só contando a história de todas as mulheres que vieram antes dela, nomeando esse passado indizível, ela conseguirá se livrar dos fantasmas que a assombram. Mais uma vez, como em A chave de casa, é preciso retornar ao passado para que o presente e, com ele, o futuro, se torne possível.

Há traumas que são geracionais, ou seja, se repetem de geração em geração. Tem uma pintora que eu adoro, chamada Charlotte Salomon, em cuja família o suicídio era uma repetição. Muitos de seus parentes desconheciam isso e acabavam cometendo suicídio sem saber que seus antepassados haviam morrido da mesma forma. Os traumas são passados mesmo que no silêncio. Eu diria que de forma mais terrível justamente quando não são nomeados.

Em Vista Chinesa, há uma mudança de ponto de vista. Antes desse romance, eu estava preocupada com a herança familiar que chegava até mim, e acabava passando isso para as minhas personagens. Depois 
que me tornei mãe, e isso aconteceu pela primeira vez em 2015, passei a me preocupar muito com o legado que os meus filhos vão receber, daí a ideia de escrever um romance-carta. Estou há 5 anos dizendo que vou escrever uma carta para o meu filho, contando coisas que eu gostaria que ele soubesse caso eu morra de repente. Até hoje, não escrevi nem uma linha. Então pensei: olha, vou escrever uma carta para os filhos da Júlia, a protagonista de Vista Chinesa. A carta, nesse romance, é uma forma de dar nome às coisas, uma tentativa de interromper o mal.

\section{P.: As suas narrativas geralmente têm uma estrutura} fragmentada, com lacunas que desafiam a imaginação dos leitores. Como é o seu processo de escrita?

R.: Minha escrita tem essa estrutura fragmentada, porque é a forma com a qual eu mesma vejo e apreendo o mundo. Virginia Woolf pensava a sua escrita como "cenas". Eu também utilizaria a mesma palavra para descrever a minha - mas, no caso dela, eram cenas da primeira metade do século $\mathrm{XX}$; no meu caso, cenas de um século depois, ou seja, muito mais fragmentadas, velozes, curtas. Minhas cenas começam mais vezes, acabam mais rapidamente, porque todos nós, hoje, vemos tudo numa velocidade muito maior do que se via cem anos atrás. 
A escrita se faz com o corpo do seu tempo. Mas o que há de comum nessa ideia da "cena" é a ideia de visualidade, que pode ser transmitida num excesso de detalhes ou com as lacunas, desde que os detalhes presentes sejam muito precisos. É isso que busco, no meu processo de escrita. Escrevo sempre a partir de uma imagem. Procuro as palavras certas para transformá-las em língua, linguagem. Mas me atenho ao que é essencial nela, como se a imagem fosse única, como se antes e depois dela não houvesse outra imagem. Ou houvesse apenas na imaginação do leitor.

P.: O mundo não vai acabar (2017) reúne textos que você escreveu para a sua coluna no jornal Valor Econômico e alguns textos inéditos. Nessa coluna você fala de literatura, indica livros e se posiciona em relação a temas atuais. Eu gostaria que você comentasse a sua atuação como colunista, que, por sinal, encontra muita receptividade junto ao público leitor.

R.: Escrevo para o Valor Econômico desde 2014, e foi uma forma que encontrei, num momento em que estava fora da universidade, de retomar a minha atividade crítica. Confesso que não gosto da vida acadêmica com todas as suas burocracias; nem me 
considero uma grande professora. Mas gosto muito do exercício crítico, e sentia falta disso. Por isso, encarei o desafio da coluna com entusiasmo. Nela, encontrei um equilíbrio entre a crônica, a teoria e a crítica, com leves doses de ficção e autobiografia.

É uma forma que tenho de manter atualizada a minha leitura de teoria literária, de filosofia e de comentar os textos literários que me interessam e me fazem pensar sobre o presente. Textos que podem ser contemporâneos ou não. Busco também comparar textos, misturar teoria com ficção. Enfim, é um privilégio que um jornal ainda mantenha um espaço para análises mais longas de literatura - sinal de que, apesar de tudo, ela ainda está viva, e ainda há quem se interesse por ela.

P.: Paraíso, já no título, pode ser lido de várias formas: literalmente, é o sítio para onde se retiram alguns personagens deslocados, como Ana, Daniel e Rosa; é também uma forma alegórica de pensar a nação, um país da promessa bucólica desmentida pelo histórico de violências e experiências traumáticas; e é também um título ambíguo e talvez irônico, já que o que se narra ali - no Paraíso - é quase sempre atravessado por uma violência desmedida, poderíamos dizer, atávica. Mas é 
também, de certa forma, a história de cinco gerações de mulheres, de suas experiências no tempo-espaço histórico. Você poderia nos falar um pouco sobre o processo de criação desse romance?

R.: Eu tinha ouvido de uma amiga a história de uma maldição lançada por uma escrava à sua família, que era dona de uma fazenda de café na região do Vale da Paraíba. Essa escrava teria sido uma rainha na sua tribo de origem, e o peso da sua palavra valeria ainda mais por isso. Ela tinha sido enterrada viva pela sinhá, que morria de ciúmes da paixão do marido por ela, mas, antes de morrer, teria lançado uma maldição sobre várias gerações de mulheres da sua família. A minha amiga pertenceria à última.

Como eu disse, sempre me interessei pelos traumas que passam de geração em geração. Esses traumas intergeracionais não deixam de ser uma espécie de maldição, algo que se repete, e com o qual já nascemos. Não é uma escolha nossa. O que podemos escolher - e Derrida fala muito bem sobre isso - é o que fazer com essa herança, com esse arquivo que herdamos.

Pedi emprestada a história a essa amiga, porque ela me interessava pessoalmente - como lidar com uma palavra 
que marca tantas gerações, como se livrar dela. A narrativa, o romance, surge para contar a história dessas mulheres marcadas pela maldição, de que forma elas a superaram, qual a força de cada mulher, mas também o que marcou historicamente a época de cada uma. Ana, a protagonista, precisa entender o passado da sua família e o passado do seu país para entender a si própria.

P.: Em uma entrevista que você concedeu recentemente, afirmou que a violência contra as mulheres é herdada e está na memória do corpo feminino. Os casos de violência contra a mulher no Brasil têm aumentado muito, e, muitas vezes, são atribuídos ao comportamento das vítimas, isso faz com que muitas se calem. Nesse sentido, Vista chinesa traz à baila duas questões importantes, ambas delicadas: a necessidade de denunciar o crime e a responsabilidade ao fazer o reconhecimento de quem o cometeu. $\mathrm{O}$ modo como você descreve a angústia de Júlia é impactante. Como foi para você escrever, depois falar, dar entrevistas, reinscrever a experiência de colocar no papel algo tão delicado e ao mesmo tempo monstruoso e traumático, que é a violação do corpo, cujos reflexos se manifestam em tantos e variados aspectos da vida da pessoa violentada? 
R.: Paraíso já era sobre essa violência. Quando terminei - livro, me dei conta de que a grande maldição era a violência contra a mulher, praticada contra a escrava e contra as outras mulheres, ao longo daqueles anos todos. Em Vista Chinesa, exploro isso mais radicalmente, pois o romance se concentra nisso, o estupro é o eixo do livro.

Eu tive a ideia de escrever o livro em março de 2015, quando, por ocasião do salão do livro de Paris, vi a exposição "Os Inocentes", de Taryn Simon, em que ela mostra retratos de pessoas presas injustamente a partir de reconhecimentos fotográficos. Esse trabalho me remeteu à investigação policial que se seguiu ao estupro da minha amiga Joana Jabace e, daí, surgiu o romance. Duas semanas depois, me descobri grávida do meu primeiro filho. Se tem uma coisa que chega junto com a alegria do primeiro filho é o sentimento de culpa. Fiquei com medo de passar sentimentos ruins para ele e suspendi a escrita. Tomei apenas algumas notas e adiei o projeto.

Exatos três anos depois, fiquei grávida de novo. Dessa vez de uma menina. Então, inesperadamente, aconteceu o contrário: senti uma necessidade de escrever. Escrevi junto com a minha filha. Com ela na barriga, depois com ela no meu peito. Sinto como se, esse livro, eu tivesse 
escrito com a companhia de muitas mulheres, das que vieram antes de mim e das que estão chegando.

Quando me veio a ideia do romance, nunca pensei em descrever a cena do estupro com tantos detalhes. Aliás, eu nem sequer pensava em descrevê-la. De forma geral, eu diria que a boa literatura, assim como o bom cinema, deixa a cargo da imaginação do leitor e do espectador as cenas mais violentas, mais traumáticas. Quando mostramos demais, corremos o risco de anular o efeito que desejamos, ou seja, corremos o risco de distanciar o leitor da dor, do horror, daquilo que costumamos chamar de indizível. Se é indizível, então, o melhor é não dizêlo, apenas evocá-lo. Às vezes, quanto menos palavras melhor: mas as palavras certas, para que o leitor possa imaginar sem se afastar.

Essa sempre foi, inclusive, a minha concepção de literatura. Até Vista Chinesa, sempre procurei dizer o máximo com o mínimo de palavras, seguindo o fluxo da retomada do sublime kantiano nas artes desde a segunda metade do século XX. Mas aí comecei a entrevistar a Joana para o livro. Estávamos em 2018, e já não falávamos sobre o assunto desde 2014. Aliás, ela não falava mais sobre isso com ninguém. Quando 
começamos as entrevistas, fiquei impressionada com a precisão dos detalhes que ela relatava.

Então, entendi que a dor estava presente, não de forma genérica, mas minuciosa. Cada detalhe doía. Dentro dela, mas também fora, na superfície, na pele, nos poros, todos os dias, a cada hora do dia. Mesmo quando ela estava feliz, a dor vinha junto. Então me vi diante de um dilema: eu não queria correr o risco de afastar o leitor com tantos detalhes, mas eu não podia fugir deles.

Percebi que não seria possível evitar a cena do estupro, como eu pretendia inicialmente. Seria necessário contála, e em detalhes. Ao mesmo tempo, eu precisava segurar na mão do leitor e levá-lo para o centro da cena sem que ele quisesse sair correndo. Precisava criar empatia, que ele desenvolvesse afeto por aquela personagem. Eu queria que a leitura despertasse no leitor o mesmo sentimento que a escrita despertou em mim: o de aproximá-lo da dor e ao mesmo tempo afastá-lo dela. Escrever tem esse poder: quando a gente encontra o tom, encontra a linguagem, é como se a gente olhasse bem nos olhos do monstro e gritasse mais alto do que ele.

Por mais que doesse em mim, eu não tinha passado pelo que a Joana passou. Eu só podia imaginar a sua dor, 
sabendo que, no fundo, a sua dor é inimaginável. Tentei, com a literatura, ser o mais verdadeira possível com o que ela me disse.

P.: Como tem sido a atividade de pesquisadora no Instituto de Filosofia da Universidade Nova de Lisboa? Qual o foco da sua pesquisa?

R.: Passei dois anos e meio trabalhando com a influência de Nietzsche na literatura; como alguns autores leram Nietzsche e mudaram o rumo de sua escrita a partir dessa leitura. Thomas Mann, Kafka, Borges, Maria Gabriela Llansol e Oswald de Andrade são alguns desses nomes. Agora, ainda estou elaborando um novo projeto sobre literatura e filosofia, que abarque a questão da representação do irrepresentável, questões ligadas à política do pensamento e da literatura.

\section{Shirley de Souza Gomes Carreira}

Doutora em Literatura Comparada (UFRJ).

Professora Adjunta do Curso de Letras da UERJ/FFP.

Docente permanente do Mestrado em Estudos Literários do Programa de Pós-graduação em Letras e Linguística da UERJ.

Líder do Grupo de Pesquisa CNPq Poéticas da Diversidade. Bolsista do Prociência UERJ/FAPERJ.

ORCID iD: https://orcid.org/0000-0002-8787-8283

\section{Paulo César Silva de Oliveira}

Doutor em Poética (UFRJ).

Professor Adjunto do Curso de Letras da UERJ/FFP. 
Docente permanente do Mestrado em Estudos Literários do Programa de Pós-graduação em Letras e Linguística da UERJ.

Líder do Grupo de Pesquisa CNPq Poéticas da Diversidade. Bolsista do Prociência UERJ/FAPERJ.

Bolsista de Produtividade do Conselho Nacional de Desenvolvimento Científico e Tecnológico - CNPq. 